\title{
Avaliação da competência comunicativa oral no Ensino Básico: Um estudo exploratório
}

\author{
Carla Monteiroi \& Fernanda Vianaii \\ Universidade do Minho, Portugal \\ Emília Moreiraiii \& Alice Bastosiv \\ Instituto Politécnico de Viana do Castelo, Portugal
}

\begin{abstract}
Resumo
A competência comunicativa oral compreende as habilidades verbais, paraverbais e não-verbais usadas para comunicar em diferentes contextos. $O$ presente estudo sustenta o uso sistemático de uma grelha de observação em sala de aula, útil para promover a formação de leitores fluentes e competentes. A amostra foi constituída por 82 alunos do $7 .^{\circ}(\mathrm{N}=61)$ e do $9 .^{\circ}$ $(\mathrm{N}=61)$ anos de escolaridade, que foram observados com recurso à grelha de Registo de Observação e Avaliação da Competência Comunicativa Oral (Monteiro, 2011a). Esta grelha apresenta três componentes da comunicação: verbal, paraverbal e não-verbal. Em termos da fiabilidade da medida, os resultados demonstram que as cotações dos professores e investigadora para a competência comunicativa oral global e para as habilidades de comunicação verbal e paraverbal estão significativamente associadas, revelando um bom acordo interjuízes. Embora os alunos do $9 .^{\circ}$ ano apresentem resultados ligeiramente superiores aos do $7 .^{\circ}$ ano, a competência comunicativa oral não difere significativamente entre estes dois grupos $(U<995,000, p>0,058)$. Verificou-se, contudo, que os alunos com melhor realização escolar em Língua Portuguesa revelam melhor competência comunicativa oral $\left[r_{s}=0,559(p<0,001)\right]$.
\end{abstract}

Palavras-chave

Competência comunicativa oral; Grelha de registo de observação e avaliação; Língua Portuguesa; Ensino Básico

\section{Competência comunicativa oral}

$\mathrm{O}$ ato de comunicar é uma competência fundamental. No entanto, será que todas as pessoas estão capazes de comunicar de forma eficaz, 
independentemente do contexto em que ocorra a interação verbal oral? Se para saber comunicar bastasse saber falar, a resposta seria positiva, mas, na verdade, o ato de comunicar oralmente é um processo muito mais complexo, que se alicerça na fala, mas não se reduz à mesma, pois exige a aquisição e o aperfeiçoamento de determinadas habilidades inerentes à competência comunicativa oral.

O conceito de competência, neste domínio da comunicação, surgiu pela mão do fundador da gramática generativa, Chomsky (1957), para se referir à aptidão que os falantes de uma língua têm para produzir e compreender um número ilimitado de frases inéditas. O conceito de competência contrapõe-se à conceção generativista clássica que a define como o conhecimento inato do sistema da língua de que um falante dispõe, deixando de ser estabelecido no plano abstrato do sistema para o ser no plano da performance, do "uso efectivo da língua em situação" (Chomsky, 1965), ou seja, como uma competência comunicativa (Hymes, 1972, 1982). Deste modo, torna-se condição sine qua non conhecer as regras da comunicação para usar a língua de forma correta nas diferentes situações com que os indivíduos se deparam diariamente, sendo necessário dominar a competência pragmática que diz respeito às regras que permitem interpretar um enunciado inserido num contexto específico. A atenção dispensada ao "poder transformador da palavra na organização da vida social" (Amor, 2003, p. 16) explica o seu fácil encontro com a pragmática que releva da conceção da língua e discurso em situação de uso, na qual o locutor, o alocutário e o contexto são as categorias principais que determinam a interpretação linguística (Levinson, 1983).

A etnografia da comunicação, corrente originária da antropologia americana que se debruçou sobre a análise do discurso, introduziu a noção de competência comunicativa, associada à capacidade que cada indivíduo possui em dominar as regras do discurso, nomeadamente a forma como falamos em determinada situação, como gerimos a palavra e selecionamos os gestos adequados ao nosso discurso e ao coenunciador (Maingueneau, 1996). Tratando-se de uma medida que depende do contexto em que a interação ocorre e que determina o grau de sucesso relativamente aos objetivos estabelecidos (Mantha \& Sivaramakrishna, 2006), a competência comunicativa permite a interação com os outros, com precisão, clareza, 
coerência, eficácia e adequação. Os mesmos autores referem que para atingir o escopo da eficácia comunicativa o locutor tem de ver reunidos diversos critérios, nomeadamente: (1) possuir a habilidade para se adequar ao contexto situacional e ser capaz de mudar o comportamento face à alteração dos objetivos traçados para a interação; (2) ser capaz de se envolver na conversa, gerindo-a; (3) possuir uma habilidade considerada fundamental no que toca à competência de interação e comunicação, a empatia, demonstrando compreender os outros e mostrando-se disponível para ajudar; (4) revelar eficácia, aqui entendida como o nível de sucesso atingido pelos interlocutores na sua interação. Por conseguinte, deve ter-se em conta, para a observação das interações, não só os aspetos verbais e/ou paraverbais (pausas, suspiros, intensidade articulatória), como também os não-verbais da comunicação (atitudes, gestos, olhar) (Mantha \& Sivaramakrishna, 2006, pp. 35-36).

A competência comunicativa refere-se à habilidade que um indivíduo tem para se dirigir a outro com clareza, coerência e eficácia. Dito de outro modo, reporta-se à capacidade que cada um possui para falar, escrever e saber selecionar as formas linguísticas mais adequadas às diferentes situações com que nos deparamos. Neste sentido, está relacionada com a capacidade de agir eficazmente numa determinada situação (Hymes, 1972), com base nos conhecimentos adquiridos, nas experiências vividas e nos comportamentos que transmitem mensagens (Mantha \& Sivaramakrishna, 2006). É à luz do conceito de competência comunicativa que o objetivo primordial da disciplina de Língua Portuguesa no Ensino Básico se concretiza, em termos do desenvolvimento da produção de textos verbais orais, aliado ao uso de símbolos não-verbais, e da compreensão e expressão oral/escrita (Sousa, 2006). Uma comunicação eficaz exige que os interlocutores envolvidos partilhem uma clara compreensão da informação trocada, sabendo adequar a sua capacidade de produzir enunciados orais ou escritos à intenção subjacente ao ato de interação.

A linguagem é a "arma de combate" através da qual o interlocutor impõe o seu pensamento, visto que é através da palavra que o Homem participa no "grande diálogo da comunicação verbal" (Rodrigues, 2002, p. 36). Em todo o discurso, está presente uma orientação social que reflete as relações interpessoais existentes ou desejadas entre aquele que fala ou 
escreve e aquele que ouve ou lê; relações que se manifestam através de comportamentos verbais, paraverbais, não-verbais (gestos, postura, entoação e vocabulário). A expressão oral, enquanto capacidade para produzir cadeias fónicas dotadas de significado e conformes à gramática da língua, implica a mobilização de saberes linguísticos e sociais, supõe uma atividade cooperativa na interação e o conhecimento dos papéis desempenhados pelos falantes em cada tipo de situação.

Para Bakhtine (1992), a palavra ocupa o papel de fenómeno ideológico na relação social, pois trata-se do veículo de comunicação da vida quotidiana, intrinsecamente ligada aos processos de produção. Os enunciados construídos a partir da interação verbal exprimem e alimentam a ideologia do quotidiano, que se expressa através das nossas palavras, atos ou gestos. À palavra não pode ser retirado o seu papel primordial na comunicação. No entanto, a interação não se circunscreve a esta, ao compreender um leque de aspetos paraverbais e não-verbais que influenciam a relação que é estabelecida com o interlocutor. Existe, de facto, uma relação dialética entre a comunicação verbal e não-verbal, comprovada pelos estudos de Braga e Silva (2006), que demonstram que a expressão do pensamento se concretiza através das palavras, de sinais paralinguísticos (entoação e o ritmo do discurso) e sinais do corpo.

\section{A competência comunicativa oral nas orientações programáticas de Língua Portuguesa}

O Programa de Língua Portuguesa do Ensino Básico (Ministério da Educação, 1991) estabelece um equilíbrio, no processo de ensinoaprendizagem, entre a comunicação oral (ouvir/falar), a leitura, a escrita e o conhecimento explícito da língua, concebendo-a como instrumento de comunicação e assegurando que a restrição da competência linguística impede a realização integral da pessoa, isola-a da comunicação e limita o seu acesso ao conhecimento. Neste âmbito, o programa prevê que, na aula de Língua Portuguesa, haja espaço para o diálogo, a cooperação e o confronto de opiniões, ao estabelecer como primeira finalidade "assegurar o desenvolvimento gradual das capacidades de expressão e compreensão em língua materna" (Ministério da Educação, 1991, p. 6). 
No texto programático referido, dos dezoito objetivos gerais apresentados para o $3 .^{\circ}$ ciclo, seis são dedicados especificamente à compreensão e expressão orais, destacando-se os dois primeiros, pelo facto de colocarem em evidência a expressão oral: "exprimir-se oralmente, de forma desbloqueada e autónoma, em função de objectivos comunicativos diversificados e comunicar oralmente tendo em conta a oportunidade, o tempo disponível e a situação" (Ministério da Educação, 1991, p. 8).

Por conseguinte, estes textos preveem que o domínio da comunicação oral se alargue progressivamente através das interações, ao expor, narrar, argumentar e explicitar saberes, acentuando-se que é a fala que permite a socialização da experiência individual.

O professor tem de consciencializar os alunos para agirem com recurso à fala, em situações de comunicação, criando momentos formais e informais da prática da oralidade, dado que é apenas através de um trabalho sistemático, explícito e intencional que a competência comunicativa é assegurada (Hymes, 1972; Núñez-Delgado, 2000) e que tem lugar o domínio progressivo de géneros formais e públicos do oral (Sim-Sim, Duarte, \& Ferraz, 1997; Ministério da Educação, 2001).

No sentido de contribuir para o desenvolvimento de atividades que promovam a comunicação oral em diferentes situações na sala de aula, os programas de Língua Portuguesa (Ministério da Educação, 1991, 2001) apresentam diversas propostas de ensino-aprendizagem, nomeadamente o diálogo, a troca de impressões, o debate, a mesa-redonda, a entrevista, a exposição e o jogo dramático. Todas estas estratégias se enraízam na fala, daí a relevância da competência comunicativa oral.

Relativamente à gestão global do tempo no $3 .^{\circ}$ ciclo, e tendo em vista o aperfeiçoamento da competência comunicativa, o Programa de Língua Portuguesa (Ministério da Educação,1991, p. 83) dedica uma fatia de $25 \%$ do tempo letivo à comunicação oral e a mesma proporção de tempo à leitura e escrita. Os restantes $25 \%$ distribuem-se pelo conhecimento explícito da língua, programação e avaliação. Quanto à comunicação oral, $75 \%$ são dedicados à expressão verbal em interação, enquanto os restantes $25 \%$ dizem respeito à compreensão de enunciados orais. $\mathrm{Na}$ verdade, o desenvolvimento de uma expressão oral adequada exige que os professores cumpram o que o programa veicula, que promovam espaços letivos 
dedicados a atividades de dicção, recitação, exposição, dramatização e argumentação, e que se reconheça o papel relevante da aula de Língua Portuguesa na formação de leitores fluentes, competentes e críticos. Este objetivo é apenas alcançado através do diagnóstico, prática, exercício e domínio de vários saberes, do ensino de técnicas de oralidade, leitura e escrita, visando a mobilização dos conhecimentos, experiências, atitudes e valores que individualizam os alunos.

De salientar que entre os textos programáticos de 1991 e o Novo Programa de Português para o Ensino Básico (NPPEB) (Reis, 2009) foram implementados o Plano Nacional de Leitura (Ministério da Educação, 2006a) e o Programa Nacional do Ensino do Português - PNEP (Ministério da Educação, 2006b), e produzidos documentos e realizados eventos relevantes para a formalização deste domínio da língua (Sim-Sim, Duarte, \& Ferraz, 1997; Ministério da Educação, 2001; o Dicionário Terminológico; a Conferência Internacional de Ensino de Português, 2007).

Embora o domínio ouvir/falar surja, nos programas de 1991, a par do ler/escrever, a oralidade torna-se uma competência autónoma em 2001, com o Currículo Nacional do Ensino Básico (Ministério da Educação, 2001), subdividindo-se em compreensão oral e expressão oral, o que se reflete também no NPPEB (Reis, 2009). Este último refere-se ao termo competência como um conjunto de conhecimentos e capacidades e realça as competências linguístico-comunicativas como aquelas que permitem o relacionamento com os outros. A atividade linguística oral é avaliada com base na compreensão oral, consistindo na capacidade para atribuir significado a discursos orais em diferentes variedades do português e envolve a receção e a descodificação de mensagens por acesso ao conhecimento organizado na memória, e na expressão oral, compreendendo (Reis, 2009, p. 16):

"(...) a capacidade para produzir sequências fónicas dotadas de significado e conformes à gramática da língua. Esta competência implica a mobilização de saberes linguísticos e sociais e pressupõe uma atitude cooperativa na interacção comunicativa, bem como o conhecimento dos papéis desempenhados pelos falantes em cada tipo de situação".

No âmbito deste domínio, e à luz do conceito de performance (Chomsky, 1965; Hymes, 1972, 1982), o NPPEB discrimina um vasto leque de descritores de desempenho, nomeadamente: (a) planificar o uso da palavra 
em função da situação, das intenções de comunicação específicas e das características da audiência visada; (b) organizar o discurso, assegurando a progressão de ideias e a sua hierarquização; (c) produzir textos orais de diferentes tipos; (d) usar da palavra com fluência e correção, utilizando recursos verbais e não-verbais adequados às situações de comunicação; (e) diversificar o vocabulário e as estruturas utilizadas no discurso, com recurso ao português-padrão; (f) assumir diferentes papéis em situações de comunicação, adequando as estratégias discursivas às funções e objetivos visados (Reis, 2009, p. 121).

A promoção da observação e da análise do uso da língua, em sala de aula, facilitará a tomada de consciência por parte dos alunos de que a fala se constrói no âmbito de práticas dialógicas, aprofundando-se a capacidade de fazer escolhas adequadas às intenções comunicativas e aos interlocutores. De acordo com o Decreto-Lei 6/2001, de 18 de janeiro, o Currículo Nacional do Ensino Básico (CNEB) (Ministério da Educação, 2001) afirma ser necessário "garantir a cada aluno, em cada ciclo de escolaridade, o desenvolvimento de competências específicas no domínio do oral (compreensão e expressão oral), do modo escrito (leitura e expressão escrita) e do conhecimento explícito da língua" (p. 32). Além disso, Sim-Sim, Duarte, e Ferraz (1997, p. 72) acrescentam que, para atingirem o objetivo de desempenho "fluência e adequação da expressão oral em contextos formais", os alunos devem ser capazes de comunicar em situações sociais formais; adequar o discurso ao seu objetivo comunicativo e auditório; utilizar o Português Padrão nas situações de interação social que o exigem e selecionar a complexidade gramatical e o vocabulário requeridos nos géneros do oral, essenciais para prosseguirem estudos e serem cidadãos ativos.

Tendo sido revogado o "Currículo Nacional do Ensino Básico Competências Essenciais" pelo Despacho n. ${ }^{\circ} 17169 / 2011$ e tendo por base o Novo Programa de Português para o Ensino Básico, foram homologadas as Metas Curriculares de Português para o Ensino Básico - Despacho n. ${ }^{\circ}$ 10874/2012 - que esclarecem que aspetos dos Programas se devem eleger como prioridade no ensino e aprendizagem, definindo os conhecimentos a adquirir e as capacidades a desenvolver pelos alunos em cada ano de escolaridade. As Metas Curriculares (Buescu, Morais, Rocha, \& Magalhães, 2012) contêm cinco domínios de referência no $3 .^{\circ}$ ciclo (Oralidade, Leitura, 
Escrita, Educação Literária, Gramática). Realce-se, neste documento, o estabelecimento de descritores de desempenho dos alunos que permitam avaliar a consecução dos objetivos. Quanto à Oralidade, a especificidade dos descritores de desempenho é evidente, nomeadamente ao exigir que os alunos do $7 .^{\circ}$ e $8 .^{\circ}$ anos produzam textos orais em quatro minutos (mínimo) e os do $9 .^{\circ}$ ano em cinco minutos.

Considerando os documentos normativos e textos programáticos estabelecidos para o ensino básico, é cada vez mais notória a preocupação política em evidenciar as competências específicas da compreensão e expressão oral. Note-se, porém, que o NPPEB não faz qualquer referência a estratégias e métodos de avaliação, o que foi justificado, na Conferência Internacional de Ensino de Português, em 2007, pela premência de os programas integrarem uma escala de critérios de avaliação contínua da oralidade, em detrimento da definição de critérios de avaliação. Este 'vazio' acaba por dificultar a tarefa aos professores, uma vez que seria mais prático e objetivo se existissem não só critérios bem definidos, como também instrumentos de avaliação válidos e eficazes. Pelo contrário, no ensino secundário, na disciplina de Português, a avaliação da oralidade é de caráter obrigatório e regulamentada pela Portaria 1322/2007, de 4 de outubro. Nos termos da alínea a) do . $^{\circ} 6$ do artigo $9 .^{\circ}$, "são obrigatórios momentos formais de avaliação da oralidade ou da dimensão prática ou experimental, integrados no processo de ensino-aprendizagem, de acordo com as alíneas seguintes: a) $\mathrm{Na}$ disciplina de Português a componente de oralidade tem um peso de $25 \%$ no cálculo da classificação a atribuir em cada momento formal de avaliação (...)".

Neste sentido, torna-se relevante a promoção desta competência no ensino básico; porém, apesar da maior importância atribuída à competência comunicativa oral no Programa de Português do $3 .^{\circ}$ ciclo do Ensino Básico (Reis, 2009) e de ser possível, com base nas Metas Curriculares, uma crescente objetividade no momento de avaliar determinados conteúdos e habilidades, não é estipulada uma percentagem específica de tempo letivo para a avaliação dos vários domínios contemplados. Assim sendo, quando se 'desce' das políticas educativas ao contexto escolar, parece surgir um paradoxo, na medida em que a oralidade não possui o mesmo tratamento que é dado às competências da leitura e da escrita. A expressão oral não é alvo de planificação e ensino sistemáticos, nem de observação ou avaliação 
formativa, o que faz transparecer um "desprestígio pedagógico da comunicação" (Sousa, 2006, p. 22) e espelha uma postura passiva face ao desenvolvimento da comunicação oral, com consequências ao nível da competência dos alunos, nomeadamente a falta de fluência, assim como a incorreção ou pobreza lexical, e das próprias competências relacionais e sociais.

\section{A competência comunicativa oral em sala de aula: instrumentos de avaliação}

A sala de aula constitui-se um espaço comunicativo caracterizado por relações explícitas ou implícitas entre participantes e tornadas visíveis através das estratégias linguísticas e paralinguísticas utilizadas pelos atores. $O$ processo de ensino-aprendizagem que se desenvolve neste contexto estabelece-se sob a forma de interação social dependente da comunicação (Castro, 1989). Apesar da defesa corrente em torno da abertura da sala de aula a uma interação comunicacional dinâmica entre professor-alunos, estudos revelam que o professor acaba por falar mais do que os alunos, utilizando enunciados mais longos (Castro, 1991; Núñez-Delgado, 2000; Pedro, 1992; Sousa, 2006). O professor é, classicamente, o principal solicitador e estruturador, limitando o desenvolvimento da competência de comunicação por parte do aluno. O processo de comunicação pedagógica não deve reduzir-se a uma estrutura linear e inflexível. No entanto, parece prevalecer nas nossas escolas uma comunicação assente numa "unidade nuclear" (Castro, 1989, p.16), numa troca, que compreende os movimentos de abertura, resposta e fechamento, tornando-se o professor no locutor por excelência.

Os alunos esperam que a aula se torne num espaço que privilegie a interação, no qual eles desejam ser também emissores. Esta interação verbal resulta de uma aprendizagem, na medida em que tal como se aprende a ler e a escrever também se aprende a estruturar enunciados orais, socialmente reconhecidos e instituídos. Num dado contexto de comunicação, como o de sala de aula, locutor e alocutário são ativos, com as suas especificidades e, apesar destas diferenças, não podem deixar de cooperar "pois comunicar é uma actividade que Ihes é comum" (Grize, 1996, p. 77). 
O estudo e promoção da competência comunicativa em sala de aula implicam a produção de um discurso num determinado contexto, logo a avaliação do discurso - através de instrumentos, como grelhas de observação ou registos do conteúdo do discurso - deverá contemplar um conjunto de fatores pessoais, funcionais, curriculares, bem como aquisições prévias. Neste contexto, deverá focar-se nas componentes da comunicação/interação, analisando aspetos verbais, paraverbais e não-verbais. Esta avaliação deve ser realizada em momentos formais, previamente agendados, nos quais os alunos poderão desenvolver a sua competência com base na concretização de inúmeras atividades. Com o objetivo de verem a sua participação na aula concretizada de modo eficaz, os alunos poderão proceder a relatos de acontecimentos vividos, visionados ou inventados, a jogos de faz de conta, a exposições orais, argumentações, debates, diálogos e dramatizações (Sousa, 2006). A discussão é também considerada uma estratégia eficaz para o desenvolvimento da competência comunicativa oral, visto que permite trabalhar a argumentação oral, desenvolver a compreensão, aumentar o vocabulário e aperfeiçoar a expressão (Núñez-Delgado, 2000). Para tornar estas atividades ainda mais vantajosas para a prática e aperfeiçoamento da competência comunicativa oral, deverão ser previamente preparadas mediante um plano-guia.

A avaliação objetiva das competências comunicativas revela-se uma ferramenta básica para o estabelecimento de um plano de ação centrado no aluno e orientado para o aperfeiçoamento da sua competência comunicativa oral. Neste sentido, têm de ser criadas as condições para a apropriação de mecanismos linguísticos disponíveis, o que implica definir, na sala de aula, situações de comunicação que envolvam os vários processos comunicativos - ler, escrever, falar, ouvir (Castro, 1991) e compreender. Neste âmbito, importa analisar os instrumentos disponíveis para o trabalho do professor em sala de aula.

Em Portugal, há uma escassez de estudos sobre a construção e validação de instrumentos de apoio pedagógico-didático no domínio da competência comunicativa oral (Amor, 2003). Ao nível europeu, destacam-se os trabalhos desenvolvidos em França e Espanha no sentido da produção de materiais dirigidos à prática sistemática de atividades de avaliação e promoção da compreensão e expressão oral nas escolas (Lomas, 2002; Núñez-Delgado, 2000, 2005; Reyzábal, 1988; Roulet, 1991). 
No contexto nacional, têm surgido investigadores que demonstram preocupação com o desenvolvimento de instrumentos que permitem apoiar 0 ensino sistemático da comunicação oral, nomeadamente o trabalho desenvolvido por Sousa (2006). Contudo, a maioria dos estudos parece incidir sobre a presença ou ausência, nos manuais, de atividades que desenvolvam a expressão oral ou sobre estratégias de treino do oral (Silva, 2008).

No que concerne aos instrumentos de avaliação, as grelhas de observação e avaliação devem ser usadas como estratégias de tratamento pedagógico-didático da expressão oral, pois baseiam-se em fundamentos teóricos consistentes, complementados pela sua funcionalidade e adequação prática ao contexto (Lomas, 2002; Núñez-Delgado, 2005; Sousa, 2006).

A avaliação da comunicação oral com base numa grelha de observação e em registos exige que estes instrumentos sejam operacionais, fiáveis e capazes de traduzir com rigor o nível de desempenho dos alunos. Uma avaliação quantitativa não consegue espelhar na íntegra a qualidade de todos os dados recolhidos acerca de uma produção oral. A complementaridade de uma avaliação qualitativa, sistemática e rigorosa permitirá reunir evidências sobre as componentes verbal, paraverbal e nãoverbal da comunicação (Monteiro, 2011a, 2011b; Monteiro, Moreira \& Bastos, 2011b). Foi com o objetivo de construir um instrumento válido e fidedigno que se elaborou a presente Grelha de Registo de Observação e Avaliação da Competência Comunicativa Oral.

\section{Método}

\section{Participantes}

No presente estudo, realizado durante o segundo período do ano letivo 2010/2011, participaram alunos do $3 .^{\circ}$ ciclo do ensino básico de uma escola básica e secundária de Portugal, do distrito de Viana do Castelo.

A amostra global ( $\mathrm{N}=82)$ apresenta uma média de idade de 13,26 anos $(\mathrm{DP}=1,06)$, variando entre 12 anos no $7 .^{\circ}$ ano $(\mathrm{DP}=0,66)$ e 14 anos no $9 .^{\circ}$ ano $(\mathrm{DP}=0,38)$. Cerca de $50 \%$ dos alunos são do género feminino $(51,2 \%)$, sendo esta proporção ligeiramente superior no $9 .^{\circ}$ ano $(56,1 \%)$, apesar das diferenças na distribuição de género não serem estatisticamente significativas $\left(x^{2}=0,78, g l=1, p=0,377\right)$. 


\section{Instrumentos}

$\mathrm{Na}$ ausência de instrumentos de avaliação objetiva da competência comunicativa oral, foi elaborada a Grelha de Registo de Observação e Avaliação da Competência Comunicativa Oral (Anexo A), tendo por base modelos aplicados no ensino secundário. Este instrumento, destinado a momentos de exposição oral - explicação, argumentação e debate - reportase à comunicação verbal (60\%), paraverbal (30\%) e não-verbal (10\%). Procedeu-se a esta distribuição percentual com base na opinião dos professores de Língua Portuguesa envolvidos no estudo ${ }^{1}$ e de outros pertencentes ao Departamento de Línguas, e em grelhas de avaliação deste domínio construídas por professores/formadores. Relativamente ao primeiro domínio, os parâmetros observados e avaliados são o conhecimento do tema, o vocabulário (riqueza e diversidade), a argumentação pertinente, a clareza discursiva (articulação clara das palavras, segundo a norma padrão e sem hesitações) e o respeito pelas opiniões alheias; no segundo domínio, são avaliados os parâmetros da clareza discursiva, expressividade, tom de voz e ritmo discursivo; por último, ao nível da comunicação não-verbal, são avaliados os gestos, o olhar e a postura corporal. Todos os parâmetros são avaliados com base na escala de avaliação qualitativa formativa - Fraco (1), Não Satisfaz (2), Satisfaz (3), Satisfaz Bastante (4) e Excelente (5) -, convertida, em última análise, numa classificação quantitativa, mais conveniente para o momento de avaliação final dos períodos.

A grelha em anexo, cujos critérios de classificação se baseiam nos estabelecidos pelo Gabinete de Avaliação Educacional (GAVE) para o grupo "expressão escrita" do exame nacional de Língua Portuguesa $-9 .^{\circ}$ ano de escolaridade, com as devidas adaptações para a expressão oral, apresenta os indicadores e níveis de desempenho a ter em conta na observação e avaliação da competência comunicativa oral (CCO). Os níveis intermédios, aos quais correspondem os níveis Satisfaz Bastante (4) e Não Satisfaz (2), não foram explicitados, com o objetivo de permitir uma maior flexibilidade na avaliação das diferentes habilidades de comunicação (Anexo B).

Além disso, tentou-se chegar à conclusão sobre uma possível relação da competência comunicativa oral com os resultados escolares, procurando responder à questão "Será que os alunos que apresentam melhores resultados escolares são aqueles que obtêm valores mais elevados ao nível 
da competência?". Com a finalidade de analisar as relações entre a competência comunicativa oral e os resultados escolares, em alunos do $3^{\circ}$ ciclo do ensino básico $\left(7 .^{\circ}\right.$ e $9 .^{\circ}$ ano de escolaridade), foram considerados os níveis obtidos na disciplina de Língua Portuguesa, em resultado da avaliação do $2 .^{\circ}$ período.

\section{Procedimentos}

Relativamente à Grelha de Registo de Observação e Avaliação da Competência Comunicativa Oral, procedeu-se, em conjunto com o professor de Língua Portuguesa das 4 turmas, ao agendamento e preparação de momentos formais de exposição oral, com o objetivo de aplicar a grelha a uma situação criada para o efeito. Foi assegurado que todos os alunos se expressassem oralmente para se cumprir o propósito da investigação.

No que diz respeito às turmas do $7 .^{\circ}$ ano, devido ao nível de ensino em questão, ao perfil dos alunos e à deficiente prática da oralidade em momentos formais, considerou-se conveniente haver lugar a uma discussão aberta à turma, em que todos tivessem a oportunidade de expor a sua opinião. Como fator de motivação para a discussão, considerou-se relevante que os alunos propusessem um tema que lhes despertasse o interesse, o que foi feito, tendo sido selecionados como temas a presença da Língua Portuguesa em países de língua oficial portuguesa, em concreto Cabo Verde, alargando o tema às condições nas escolas, culturas e tradições, numa turma, e à prática de desporto, na outra turma.

Numa das turmas de $9 .^{\circ}$ ano, com o objetivo de não prejudicar a sequência didática programada, estabeleceu-se que os alunos apresentassem oralmente, de forma individual, os trabalhos de grupo desenvolvidos no âmbito da temática O Auto da Barca do Inferno, de Gil Vicente. Cada elemento expôs uma parte do trabalho desenvolvido sob orientação da professora. Na outra turma, a professora estipulou, em conjunto com os alunos, que a apresentação teria lugar com base num tema que gostassem de desenvolver. Os alunos tomaram conhecimento do tipo de comunicação oral a realizar, dos aspetos que iriam ser sujeitos a observação e das várias etapas a percorrer, desde a seleção do tema, passando pela pesquisa de informações, até à estruturação e conclusão do trabalho 
desenvolvido. Várias foram as temáticas afloradas, nomeadamente desporto, problemas relacionados com a adolescência e gosto pela leitura.

Concluídos os trabalhos, foi agendado o dia para a observação e avaliação da comunicação oral, no qual estiveram presentes o(a) respetivo(a) professor(a) e a investigadora, observando ambos e avaliando as componentes da oralidade que integram a grelha em uso. À medida que o(a) professor(a) da turma orientava os alunos na prossecução dos trabalhos, o(a) mesmo(a) e a investigadora estavam posicionados no fundo da sala de aula, guardando uma distância que não comprometia a imparcialidade no momento da avaliação. Com recurso ao computador e à Grelha de Observação e Avaliação em formato Excel, a performance comunicativa dos alunos era observada e avaliada nos diferentes parâmetros que integram a comunicação verbal, paraverbal e não-verbal, atribuindo-se a respetiva menção da escala Fraco (1), Não Satisfaz (2), Satisfaz (3), Satisfaz Bastante (4) e Excelente (5) - com base nos indicadores estabelecidos (Anexo B). A gravação em vídeo não foi considerada para não pôr em causa a espontaneidade dos alunos.

Quanto à análise dos dados, usou-se, na análise descritiva, a frequência absoluta e a proporção como medida sumária para variáveis qualitativas e a média e desvio-padrão para variáveis quantitativas, acompanhada do desvio-padrão, como medida de dispersão. Quando a variável não seguia a distribuição normal (teste de Kolmogorov-Smirnov), a distribuição foi descrita pela média e $1^{\circ}$ e $3 .^{\circ}$ quartis. Para testar a independência entre duas variáveis categóricas, usou-se o teste quiquadrado; para averiguar a igualdade de médias o teste $t$ student para amostras independentes ou o teste $U$ Mann-Whitney para comparação de variáveis que não seguiam distribuição normal.

Para avaliar a relação entre as duas observações, os dados relativos às observações da competência comunicativa oral (comunicação verbal, paraverbal, não-verbal e total) da investigadora e dos professores foram correlacionados, funcionando como um indicador de acordo. Para tal, foi utilizada a correlação $r_{s}$ de Spearman, uma vez que as variáveis não seguiam distribuição normal. Foi ainda realizado o teste Wilcoxon para amostras emparelhadas para avaliar a significância das duas medições realizadas pela investigadora e pelos professores. Como todas as correlações entre os resultados atribuídos pela investigadora e professores foram elevadas 
$(r=0,70)$ e ambas as cotações revelaram ser semelhantes para todos os domínios da grelha, com exceção da comunicação não-verbal, optou-se por prosseguir as restantes análises com base nas observações dos professores. Os resultados da competência comunicativa oral foram descritos para os alunos de $7 .^{\circ}$ e $9 .^{\circ}$ ano e comparados entre si, entre grupos de género.

Os dados da realização escolar foram descritos para o $7 .^{\circ}$ e $9 .^{\circ}$ ano e correlacionados com os resultados obtidos na avaliação da competência comunicativa oral, através da correlação $r_{s}$ de Spearman (uma vez que as variáveis da competência comunicativa oral não seguiam distribuição normal).

\section{Resultados}

\section{Competência Comunicativa Oral}

A Tabela 1 apresenta a correlação entre as pontuações atribuídas por professores e investigadora relativamente aos domínios da competência comunicativa oral. Verifica-se que, para todos os domínios, a correlação entre as observações é superior a $r_{s}=0,70(\mathrm{p}<0,01)$.

Tabela 1 - Correlação interobservadores (rs de Spearman)

\begin{tabular}{lcccc}
\hline & \multicolumn{4}{c}{ Professores } \\
\hline Investigador & $\begin{array}{c}\text { Comunicação } \\
\text { verbal }\end{array}$ & $\begin{array}{c}\text { Comunicação } \\
\text { paraverbal }\end{array}$ & $\begin{array}{c}\text { Comunicação } \\
\text { não verbal }\end{array}$ & $\begin{array}{c}\text { CCO } \\
\text { global }\end{array}$ \\
\cline { 2 - 5 } & \multicolumn{2}{c}{$r_{s}$} \\
\hline Comunicação verbal & $0,926^{* *}$ & & \\
Comunicação paraverbal & & $0,968^{* *}$ & $0,718^{* *}$ & \\
Comunicação não-verbal & & & $0,814^{* *}$ \\
CCO global & & & \\
${ }^{a}$ correlação $r_{s}$ de Spearman & & & \\
$*: *(p<0,01)$ & & & & \\
\hline
\end{tabular}

As pontuações atribuídas pelos professores e investigadora à comunicação verbal e paraverbal são as mais correlacionadas $\left(r_{s}=0,926\right.$ e $r_{s}=0,968$, respetivamente). A comunicação não-verbal aparece como a observação na qual as pontuações atribuídas estão menos correlacionadas $\left(r_{s}=0,718, \mathrm{p}<0,01\right)$. Comparando as avaliações realizadas pela investigadora e pelos professores através do teste de Wilcoxon para amostras 
emparelhadas, verifica-se que ambas as cotações são semelhantes para os domínios verbal $(Z=367,000, p=0,405)$, paraverbal $(Z=233,000, p=0,992)$ e para a CCO global $(Z=59,500, p=0,617)$. No domínio não verbal, verificam-se diferenças estatisticamente significativas entre as cotações da investigadora e dos professores $(Z=916,500, p<0,001)$.

A Tabela 2 apresenta os resultados dos comportamentos de comunicação oral atribuídos pelos professores. Os diferentes parâmetros que integram as componentes da comunicação verbal, paraverbal e não-verbal são avaliados segundo a escala: Fraco (1), Não Satisfaz (2), Satisfaz (3), Satisfaz Bastante (4) e Excelente (5).

Analisando as pontuações, verifica-se que os alunos obtiveram valores médios próximos de 3 em todos as componentes da competência comunicativa oral.

Tabela 2 - Resultados da observação dos comportamentos de comunicação oral pelos professores

\begin{tabular}{|c|c|c|c|c|c|c|}
\hline & \multicolumn{2}{|c|}{$\begin{array}{l}7^{\circ} \text { ano } \\
n=40\end{array}$} & \multicolumn{2}{|c|}{$\begin{array}{l}9^{\circ} \text { ano } \\
n=40\end{array}$} & \multicolumn{2}{|c|}{$\begin{array}{c}\text { Total } \\
n=80\end{array}$} \\
\hline & $M$ & $D P$ & $M$ & $D P$ & $M$ & $D P$ \\
\hline \multicolumn{7}{|l|}{ Dimensões } \\
\hline Comunicação verbal & 2,9 & 0,81 & 3,1 & 0,59 & 3,0 & 0,71 \\
\hline Comunicação paraverbal & 2,9 & 0,77 & 3,0 & 0,65 & 2,9 & 0,71 \\
\hline Comunicação não verbal & 2,8 & 0,71 & 2,9 & 0,53 & 2,8 & 0,63 \\
\hline Total & 2,9 & 0,82 & 3,0 & 0,65 & 3,0 & 0,74 \\
\hline \multicolumn{7}{|l|}{ Classificação $n(\%)$} \\
\hline Fraco (1) & \multicolumn{2}{|c|}{--} & \multicolumn{2}{|c|}{--} & \multicolumn{2}{|c|}{--} \\
\hline Não Satisfaz (2) & \multicolumn{2}{|c|}{$9(22,5)$} & \multicolumn{2}{|c|}{$2(5,0)$} & \multicolumn{2}{|c|}{$11(13,8)$} \\
\hline Satisfaz (3) & \multicolumn{2}{|c|}{$22(55,0)$} & \multicolumn{2}{|c|}{$32(80,0)$} & \multicolumn{2}{|c|}{$54(67,5)$} \\
\hline Satisfaz Bastante (4) & \multicolumn{2}{|c|}{$9(22,5)$} & \multicolumn{2}{|c|}{$6(15,0)$} & \multicolumn{2}{|c|}{$15(18,8)$} \\
\hline Excelente (5) & \multicolumn{2}{|c|}{-- } & \multicolumn{2}{|c|}{-- } & \multicolumn{2}{|c|}{-- } \\
\hline
\end{tabular}

Cerca de $68 \%$ dos alunos obteve classificação global Satisfaz, 18,8\% obteve classificação de Satisfaz Bastante e 13,8\% de Não Satisfaz; não foi atribuído qualquer nível Fraco ou Excelente por parte dos avaliadores. A média dos alunos de $9 .^{\circ}$ ano é ligeiramente superior à dos de $7 .^{\circ}$ ano para 
todas as dimensões e para a escala global, apesar de as diferenças não serem estatisticamente significativas $(U<995,000, p>0,058)$.

Comparando rapazes e raparigas, verifica-se que os resultados são relativamente semelhantes entre ambos os grupos, com exceção da comunicação verbal $(U=1094,500, p=0,004)$, na qual as raparigas têm resultados superiores. As raparigas apresentam igualmente uma amplitude interquartílica mais larga do que os rapazes e $25 \%$ delas atingiu valores iguais ou superiores a 4 (raparigas: $M d=3,2$ [p25=2,2; $p 75=4,0]$ vs. rapazes: $M d=3$ [p25=2,6; p75=3,2]).

A Tabela 3 apresenta as correlações entre o desempenho dos alunos na disciplina de Língua Portuguesa e os resultados obtidos na Grelha de Registo de Observação e Avaliação da Competência Comunicativa Oral.

Tabela 3 - Correlações entre nota de Língua Portuguesa e competência comunicativa oral

\begin{tabular}{lc}
\hline & $\begin{array}{c}\text { Nota de Língua } \\
\text { Portuguesa }\end{array}$ \\
\cline { 2 - 2 } & \multicolumn{1}{c}{$r_{s}{ }^{a}$} \\
\hline Competência Comunicativa Oral & \\
Comunicação Verbal & $0,720^{* *}$ \\
Comunicação Paraverbal & $0,574^{* *}$ \\
Comunicação Não Verbal & $0,450^{* *}$ \\
Escala Global & $0,559^{* *}$ \\
${ }^{{ }^{2} \text { correlação } r_{s} \text { de Spearman }}$ & \\
${ }^{* *}(p<0,01)$ & \\
\end{tabular}

Os resultados obtidos na disciplina de Língua Portuguesa apresentam correlações positivas e estatisticamente significativas $(p<0,01)$ com todas as componentes da competência comunicativa oral. As correlações variam entre $r_{s}=0,450(p<0,01)$ com a comunicação não-verbal e $r_{s}=0,720(p<0,01)$ com a comunicação verbal.

\section{Discussão}

A Grelha de Registo de Observação e Avaliação da Competência Comunicativa Oral revelou-se um instrumento útil em contexto de sala de 
aula, uma vez que permite observar as diferentes habilidades relativas à competência comunicativa oral, avaliando-as de forma prática e eficaz. Em termos de fiabilidade da medida, verificou-se que as cotações dos professores e da investigadora estão significativamente associadas e que são dependentes entre si, o que revela um bom acordo interjuízes. No que diz respeito às habilidades de comunicação não-verbal, as cotações entre professores e investigadora apresentam uma associação mais moderada e são independentes, devendo ser alvo de novos estudos.

Tratando-se de competências cujas habilidades se desenvolvem com a prática sistemática, apesar de os alunos do $9 .^{\circ}$ ano apresentarem resultados ligeiramente superiores aos de $7 .^{\circ}$ ano ao nível da competência comunicativa oral, estas diferenças não são estatisticamente significativas. Esta semelhança entre os grupos poderá ser justificada pela ausência da prática sistemática da oralidade, pela deficiente preparação da atividade ou falta de empenho dos alunos. Seria pertinente verificar se houve lugar a desenvolvimento da competência, quer nos alunos de $7 .^{\circ}$, quer nos alunos do $9 .^{\circ}$, em relação à competência demonstrada no $5 .^{\circ}$ e $7 .^{\circ}$ anos, respetivamente - o que poderia ser comprovado com base num estudo de natureza longitudinal.

As habilidades de comunicação verbal são as que mais se correlacionam com os níveis obtidos na disciplina de Língua Portuguesa, revelando o estudo uma associação positiva e significativa entre as notas obtidas nesta disciplina e a competência comunicativa oral. Este resultado permite responder afirmativamente à questão levantada - "Será que os alunos que apresentam melhores resultados escolares são aqueles que obtêm valores mais elevados ao nível da competência?". De facto, os principais parâmetros avaliados nesta competência (o conhecimento do tema, a riqueza e diversidade vocabular, a argumentação pertinente e a coerência discursiva) são habilidades sujeitas à prática sistemática na aula de Língua Portuguesa, particularmente no domínio da escrita. Tendo em conta que alunos com dificuldades de aprendizagem tendem a ser menos habilidosos na comunicação verbal e não-verbal (Kavale \& Forness, 1996), é importante realçar, no sentido de os auxiliar na sua aprendizagem, que é "graças à aquisição da competência comunicativa oral que se desenvolve a competência comunicativa escrita, mediante uma aprendizagem sistemática 
que se apoia no conhecimento da actividade oral" (Palencia, Fernández, \& Villalobos, 2008, p. 37). Por outro lado, aquela competência também contribui para "minimizar as dificuldades na aprendizagem da Leitura e, portanto, diminuir o insucesso escolar" (Sim-Sim, 2002, p. 220).

$\mathrm{Na}$ realidade, como referem Teale e Sulzby (1992), ouvir, falar, ler e escrever desenvolvem-se de forma concorrente e inter-relacionada e não de forma sequencial.

Dada a escassez de trabalhos de investigação ao nível da competência comunicativa oral em Educação, aliada à importância que esta competência possui, quer ao nível social, quer ao nível escolar, urge empreender investigação neste domínio, tendo em vista o planeamento e implementação de programas de treino sistemático destinados à melhoria das competências de comunicação e habilidades sociais. A aprendizagem dá-se num contexto de relação social em que os alunos aprendem em colaboração com os professores e na companhia dos colegas. A tarefa de criar na aula um clima de interação efetiva, dando protagonismo aos alunos, é uma "exigência irrenunciável" (Núñez-Delgado, 2000, p. 15) e cabe aos docentes o papel de observar os alunos, incentivá-los a intervir e de organizar o espaço, de modo a permitir a comunicação entre os alunos e entre estes e o professor.

\section{Considerações finais}

O presente estudo apresenta algumas limitações na sua execução que poderão condicionar a generalização dos resultados. A avaliação da competência comunicativa oral, nas quatro turmas, ocorreu em situações de oralidade distintas - apresentação individual de trabalhos de grupo, apresentação de temas escolhidos pelo próprio e discussão de temas sugeridos; contudo, não foram identificadas diferenças estatisticamente significativas ao nível da competência comunicativa oral entre alunos das turmas de $7 .^{\circ}$ e $9 .^{\circ}$ ano. Considera-se necessário, em próximos estudos, realizar a observação em situações de oralidade similares para minimizar o viés que a própria situação poderá provocar nos resultados obtidos.

Partindo dos resultados analisados, considera-se que as comparações transversais de grupos de alunos de $7 .^{\circ}$ e $9 .^{\circ}$ ano de escolaridade poderão ser influenciadas por características dos próprios grupos. A aferição de diferenças 
desenvolvimentais ao nível da competência comunicativa oral seria idealmente realizada a partir de dados longitudinais, nos quais fosse possível controlar as diferenças interindividuais.

Os resultados obtidos corroboram a necessidade de se promover o desenvolvimento das habilidades de comunicação oral, particularmente as que integram a comunicação não-verbal. A clareza, coerência, eficácia e adequação da comunicação ao contexto são essenciais no percurso escolar e no desenvolvimento humano, estando associadas à competência de comunicação verbal, paraverbal e não-verbal. Deste modo, a comunicação oral deve ser adquirida e treinada em sala de aula, a par de outras competências.

Neste momento, urge que o professor reorganize a sua sala de aula, se afaste do quadro e do seu manual, desvie as mesas e as cadeiras e prepare momentos em que os alunos possam desenvolver as suas competências de comunicação e relação interpessoal, com recurso ao treino controlado, para, assim, se tornar possível ensinar, observar e avaliar a competência comunicativa oral. Como instrumentos de apoio, destaca-se a importância que o Programa de Português (2009) e as Metas Curriculares de Português para o Ensino Básico (2012) conferem à oralidade, assim como ao estabelecimento de descritores de desempenho e objetivos específicos, que poderão ser avaliados de forma prática e eficaz, nomeadamente com recurso à Grelha de Registo de Observação e Avaliação da Competência Comunicativa Oral.

\section{Nota}

1 Os professores foram selecionados em função de dois critérios: a) o número mais elevado alunos; b) acompanharem as turmas desde o início do ano letivo. Nos momentos de avaliação, estiveram presentes o(a) respetivo(a) professor(a) e a investigadora, que procederam à observação e avaliação individuais das componentes da oralidade que integravam a grelha (verbal, paraverbal e nãoverbal). 


\section{Referências}

Amor, E. (2003). Didáctica do Português. Fundamentos e metodologia. Lisboa: Texto Editora.

Bakhtine, M. M. (1992). Estética da criação verbal. S. Paulo: Martins Fontes.

Braga, M., \& Silva. P. (2006). Como acompanhar a progressão da competência comunicativa no aluno de Enfermagem. Revista da Escola de Enfermagem, 40, 329-335.

Buescu, H., Morais, J., Rocha, M. R., \& Magalhães, V. F. (2012). Metas Curriculares de Português $\left(1 .^{\circ}, 2 .^{\circ}\right.$ e $3 .^{\circ}$ Ciclos do Ensino Básico). Lisboa: Ministério da Educação - DGE.

Castro, R. V. (1989). A aula de Português: Um contexto especializado de comunicação. In F. Sequeira, R. Castro \& M. Sousa (Eds.), O ensino-aprendizagem do Português. Teoria e práticas (pp. 13-29). Universidade do Minho: CEDC.

Castro, R. V. (1991). Aspectos da interacção verbal em contexto pedagógico. Lisboa: Livros Horizonte.

Chomsky, N. (1957). Structures syntaxiques. Paris: Éditions du Seuil.

Chomsky, N. (1965). Aspects of the theory of syntax. Cambridge, Mass.: M.I.T. Press.

Grize, J. B. (1996). Logique naturelle et communications. Paris: PUF.

Hymes, D. (1972). On communicative competence. In J. Pride \& J. Holmes (Eds.), Sociolinguistics (pp. 269-293). London: Penguin.

Hymes, D. (1982). Towards linguistic competence. Philadelphia: Graduate School of Education, University of Pensylvania.

Kavale, K. A., \& Forness, S. R. (1996). Social Skills deficits and learning disabilities: A meta-analysis. Journal of Learning Disabilities, 29, 226-237.

Levinson, S. (1983). Pragmatics. Cambridge: Cambridge University Press.

Lomas, C. (Comp.). (2002). El aprendizaje de la comunicación en las aulas. Barcelona: Paidós Comunicación.

Maingueneau, D. (1996). Os termos-chave da análise do discurso. Lisboa: Gradiva Publicações.

Mantha, S., \& Sivaramakrishna (2006). Handbook of communication skills: Soft skills for public managers. India: Center for Good Governance, Knowlegde, Technology, People. Disponível em www.cgg.gov.in

Ministério da Educação (1991). Organização Curricular e Programas. Ensino Básico, 3. ${ }^{\circ}$ Ciclo (Vol. I). Lisboa: Ministério da Educação-DGEBS. Disponível em http://www.dgidc. minedu.pt/ensinobasico/index.php?s=directorio\&pid= 47\&ppid=3

Ministério da Educação (2001). Currículo Nacional para o Ensino Básico. Competências Essenciais. Lisboa: Ministério da Educação - Departamento de Educação Básica. Disponível em http://www.dgidc.min-edu.pt/ensinobasico/index.php?s= directorio\&pid=2

Ministério da Educação (2006a). Plano Nacional de Leitura. Lisboa: Ministério da Educação. Disponível em http://www.planonacionaldeleitura.gov.pt/pnltv/ apresentacao.php?idDoc $=1$ 
Ministério da Educação (2006b). Programa Nacional Ensino de Português. Lisboa: Ministério da Educação - DGE. Disponível em http://www.dgidc.minedu.pt/outrosprojetos/ index.php?s=directorio\&pid $=10$

Monteiro, C. (2011a). Competência comunicativa oral e competência social no ensino básico: Contributos da investigação para a inovação educacional (Dissertação de Mestrado, não publicada). Instituto Politécnico de Viana do Castelo - E.S.E, Viana do Castelo.

Monteiro, C. (2011b). Competência comunicativa oral e competência social no Ensino Básico: Investigar para inovar em educação. Comunicação apresentada em "Encontros de Avaliação e Inovação em Educação: Contributos do 'school improvement"', Instituto Politécnico de Viana do Castelo - E.S.E., 18 de junho.

Monteiro, C., Moreira, E., \& Bastos, A. (2011a). Avaliar a competência comunicativa oral na Língua Portuguesa no Ensino Básico: Estudo sobre uma grelha de observação/avaliação. Póster apresentado no XI Congresso da Sociedade Portuguesa de Ciências de Educação, Instituto Politécnico da Guarda, 30 de junho.

Monteiro, C., Moreira, E., \& Bastos, A. (2011b). Relação entre a competência comunicativa e a competência social na aula de Língua Portuguesa: Um estudo exploratório. Póster apresentado no XI Congreso Internacional GalegoPortugués de Psicopedagoxía, Universidade da Corunha, 7 a 9 de setembro.

Núñez-Delgado, M. P. (2000). Un aspecto básico para la didáctica de la lengua oral: El papel del lenguaje en la comunicación didáctica. Lenguaje y Textos, 16, 155172.

Núñez-Delgado, M. P. (2005). Comunicación y expresión oral. Hablar, escuchar y leer, en Secundaria. Barcelona: Narcea - MECD.

Palencia, I., Fernández, S., \& Villalobos, F. (2008). Dos escenarios que modelan la competencia comunicativa oral de los estudiantes de periodismo: Los docentes y el diseño curricular. Opción, 55, 28-46.

Pedro, E. R. (1992). O discurso na aula: Uma análise sociolinguística da prática escolar em Portugal. Lisboa: Editorial Caminho.

Reis, C. (Coord.). (2009). Programas de Português do Ensino Básico. Lisboa: Ministério da Educação - DGIDC.

Reyzábal, M. V. (1988). Que evaluar en la comunicación oral. Apuntes de Educación (Lengua y Literatura), 31, 6-10.

Rodrigues, D. F. (2002). Cortesia linguística: Uma competência discursivo-textual (Tese de Doutoramento, não publicada). Universidade Nova de Lisboa - Faculdade de Ciências Sociais e Humanas, Lisboa

Roulet, E. (1991). La pédagogie de l'oral en question(s). In M. Wirthner, D. Martin \& P. Perrenoud (Dir.), Parole étouffée, parole libérée. Fondements et limite d'une pédagogie de l'oral (pp.41-54). Neuchâtel: Delachaux et Niestlé.

Silva, M. F. (2008). Treino do oral formal: Entrevista e exposição no $3{ }^{\circ}$ Ciclo do Ensino Básico (Dissertação de mestrado, não publicada). Universidade do Porto Faculdade de Letras, Porto. 
Sim-Sim, I. (2002). Desenvolver a linguagem. Aprender a linguagem. In A. D. Carvalho (Org.), Novas metodologias em educação (pp. 197-226). Porto: Porto Editora.

Sim-Sim, I., Duarte, \& Ferraz, M. J. (1997). A língua materna na educação básica: Competências nucleares e níveis de desempenho. Lisboa: ME - DEB.

Sim-Sim, I. (Coord.). (2006). Programa Nacional para o Ensino do Português no $1 .^{\circ}$ Ciclo do Ensino Básico. Lisboa: Ministério da Educação - DGIDC.

Sousa, H. F. C. (2006). A comunicação oral na aula de português - Programa de intervenção pedagógico-didáctica. Porto: Edições Asa.

Teale, W. H., \& Sulzby, E. (1992). Emergent literacy: Writing and reading. Norwood, NJ: Ablex Publishing. 


\section{ASSESSMENT OF ORAL COMMUNICATIVE COMPETENCE IN ELEMENTARY SCHOOL: AN EXPLORATORY STUDY}

\section{Abstract}

The oral communicative competence comprises verbal, para-verbal and nonverbal skills, used to communicate in different contexts. The present study defends the systematic use of an observation grid in the classroom, which is useful to promote the formation of fluent and competent readers. Methodologically speaking, there were observed 82 students from the 7th and 9th grades, using the Oral Communicative Competence Observation and Assessment Register Grid (Monteiro, 2011a), which contains three communication components: verbal, para-verbal and non-verbal. In terms of the reliability of the measure, results show that the teachers' and the investigator's quotation for global oral communication competence and for verbal and para-verbal communication skills are significantly associated, revealing a good interjudgemental agreement. Even though the 9th grade students present slightly superior results from the 7th grade students, the oral communication competence do not significantly differs between these two groups $(U<995,000, p>0,058)$. Nevertheless, students with a better academic performance in Portuguese language show a better oral communicative competence $\left[r_{s}=0,559(p<0,001)\right]$.

Keywords

Oral communication competence; Observation and assessment grid; Portuguese Language; Elementary School

L'ÉVALUATION DE LA COMPÉTENCE COMMUNICATIVE ORALE AU SECOND DEGRÉ: UNE ÉTUDE EXPLORATOIRE

\section{Résumé}

La compétence communicative orale englobe les habiletés verbales, paraverbales et non-verbales utilisées pour communiquer en différents contextes. 
Cette étude soutient l'emploi systématique, en salle de classe, d'une grille d'observation nécessaire à la formation de lecteurs fluents et compétents. En thermes méthodologiques, 82 élèves de $5^{\text {ème }}(\mathrm{N}=61)$ et de $3^{\text {ème }}(\mathrm{N}=61)$ ont été observés à l'aide de cette Grille de Registre d'Observation et d'Évaluation de la Compétence Communicative Orale (Monteiro, 2011a), qui présente trois composantes de la communication: le verbal, le para-verbal et le non-verbal. En ce qui concerne la fiabilité de la mesure, les résultats démontrent que les notes attribuées par les professeurs et l'investigatrice pour la compétence communicative orale globale et pour les dextérités de communications verbales et para-verbales sont très proches, ce qui révèle une conciliation de jugements. Bien que les élèves de zème aient obtenus des résultats légèrement supérieurs aux élèves de $5^{\mathrm{ème}}$, la compétence communicative orale ne diffère pas significativement entre les deux groupes $(U<995,000$, $p>0,058)$. Cependant, les élèves ayant un meilleur rendement scolaire à la Langue Portugaise montrent une compétence communicative orale supérieure $\left[r_{s}=0,559(p<0,001)\right]$.

Mots-clé

Compétence communicative orale; Grille de registre d'observation et évaluation; Langue Portugaise; Second Degré

Recebido em agosto, 2012

Aceite para publicação em julho, 2013

i Centro de Investigação em Estudos da Criança, Instituto de Educação, Universidade do Minho.

ii Departamento de Psicologia da Educação e Educação Especial, Instituto de Educação, Universidade do Minho.

iii Escola Superior de Educação, Instituto Politécnico de Viana do Castelo.

iv Escola Superior de Educação, Instituto Politécnico de Viana do Castelo.

Toda a correspondência relativa a este artigo deve ser enviada para: Carla Monteiro, Lugar de Casais - Calheiros, 4990-575 Ponte de Lima. E-mail: carlamonteiro77@gmail.com 
$136 \mid$ Carla Monteiro et al.

\section{Anexo A}

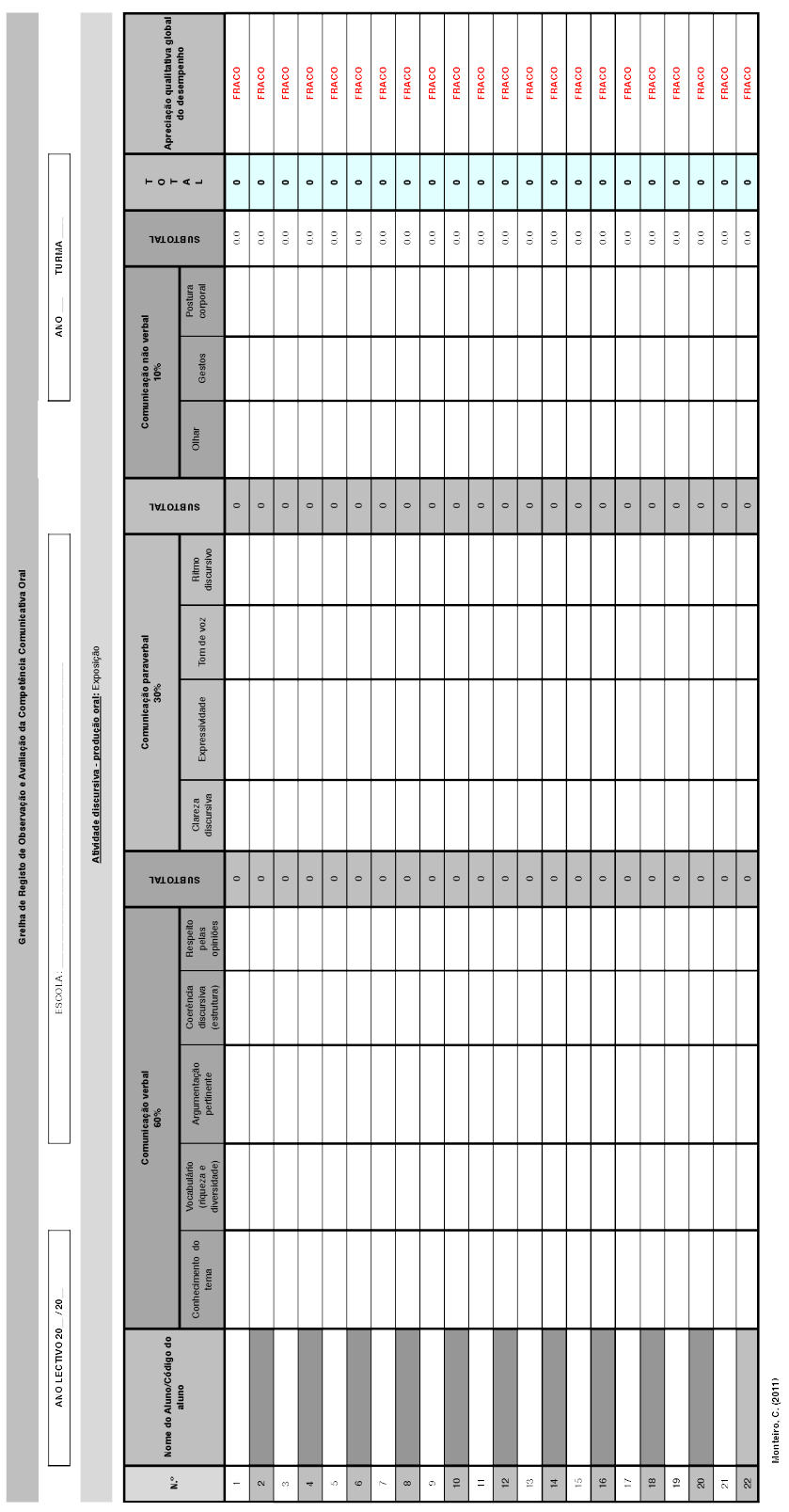




\section{Anexo B}

Anexo B - Indicadores da Grelha de Registo de Observação e Avaliação da CCO

Componente Verbal - Indicadores da Competência Comunicativa Ora

\begin{tabular}{|c|c|c|c|}
\hline \multirow{5}{*}{\multicolumn{2}{|c|}{ 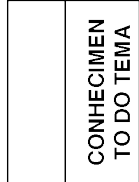 }} & 5 & Mostra integralmente ser conhecedor do tema. \\
\hline & & 4 & Nivel intermédio \\
\hline & & 3 & Mostra parcialmente ser conhecedor do tema \\
\hline & & 2 & Nivel intermédio \\
\hline & & 1 & Demonstra conhecimento insuficiente do tema \\
\hline \multirow{20}{*}{ 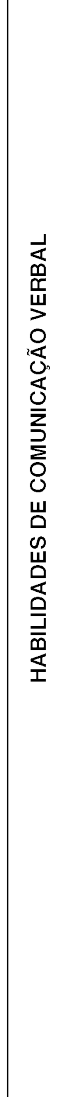 } & 으 & 5 & $\begin{array}{l}\text { Utiliza vocabulário diversificado e adequado, procedendo a uma seleção intencional de } \\
\text { vocabulário para expressar a sua opinião. }\end{array}$ \\
\hline & 焉 & 4 & Nivel intermédio \\
\hline & 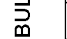 & 3 & Utiliza vocabulário adequado mas comum e com algumas confusões pontuais \\
\hline & 迈 & 2 & Nivel intermédio \\
\hline & $>$ & 1 & $\begin{array}{l}\text { Utiliza vocabulário restrito e redundante, recorrendo sistematicamente a lugares-comuns, } \\
\text { com prejúzo da comunicação. }\end{array}$ \\
\hline & 우 & 5 & $\begin{array}{l}\text { Manifesta, de forma inequívoca, um ponto de vista sobre o tema, produzindo um discurso } \\
\text { coerente, com informação pertinente, com progressão temática evidente, com abertura, } \\
\text { desenvolvimento e conclusão adequadas. }\end{array}$ \\
\hline & 迡 & 4 & Nivel intermédio \\
\hline & 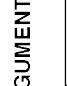 & 3 & $\begin{array}{l}\text { Produz uma comunicação que respeita parcialmente os tópicos anteriores, com alguns } \\
\text { desvios e alguma ambiguidade, produzindo um discurso globalmente coerente com } \\
\text { lacunas ou algumas insuficiências que não afetam a lógica do conjunto. }\end{array}$ \\
\hline & $\frac{\pi}{4}$ & 2 & Nivel intermédio \\
\hline & & 1 & $\begin{array}{l}\text { Produz um texto oral que desrespeita quase totalmente os tópicos dados, produzindo um } \\
\text { discurso inconsistente com informação ambígua e confusa. }\end{array}$ \\
\hline & & 5 & $\begin{array}{l}\text { Produz uma comunicação bem estruturada e articulada, recorrendo sistematicamente a } \\
\text { articuladores de discurso variados e adequados (ex. causa, explicação, oposição), } \\
\text { assegurando a manutenção de cadeias de referência (ex. substituição nominal e } \\
\text { pronominal). }\end{array}$ \\
\hline & $\overline{0}$ & 4 & Nivel intermédio \\
\hline & 㟧 & 3 & $\begin{array}{l}\text { Produz um texto bem estruturado e articulado, de forma satisfatória, recorrendo } \\
\text { assistematicamente a variados articuladores de discurso, assegurando com alguma } \\
\text { descontinuidade a manutenção de cadeias de referência. }\end{array}$ \\
\hline & & 2 & Nivel intermédio \\
\hline & & 1 & $\begin{array}{l}\text { Produz um texto oral sem estruturação aparente, organizando-o de forma muito } \\
\text { elementar, gerador de interferências na comunicação. }\end{array}$ \\
\hline & \begin{tabular}{r|c}
$\stackrel{D}{\breve{O}}$ \\
\end{tabular} & 5 & $\begin{array}{l}\text { Respeita, integralmente, as opiniões e críticas proferidas pelos colegas/audiência. } \\
\text { Coopera e responde com cortesia, de forma adequada. }\end{array}$ \\
\hline & $\overline{\underline{w}} \overline{\bar{z}}$ & 4 & Nivel intermédio \\
\hline & $\begin{array}{ll}0 \\
5\end{array}$ & 3 & Respeita parcialmente, ouve e responde, mas de forma vaga. \\
\hline & 崖孚 & 2 & Nivel intermédio \\
\hline & 㟔 & 1 & Não aceita as opiniões dos outros. \\
\hline
\end{tabular}


138 Carla Monteiro et al.

Componente Paraverbal - Indicadores da Competência Comunicativa Oral

\begin{tabular}{|c|c|c|c|}
\hline \multirow{20}{*}{ 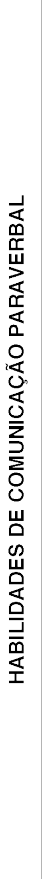 } & \multirow{5}{*}{ 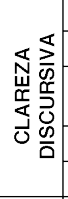 } & 5 & Produz um discurso de forma clara, objetiva e inequívoca. \\
\hline & & 4 & Nivel intermédio \\
\hline & & 3 & $\begin{array}{l}\text { Produz um discurso, com alguma clareza e de forma vaga, mas não prejudica a mensagem } \\
\text { veiculada. }\end{array}$ \\
\hline & & 2 & Nivel intermédio \\
\hline & & 1 & Produz um discurso oral confuso e indiscernivel. \\
\hline & \multirow{5}{*}{ 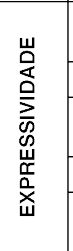 } & 5 & $\begin{array}{l}\text { Confere expressividade ao discurso, transparecendo expressões e atitudes totalmente } \\
\text { adequadas à mensagem veiculada e ao tipo de comunicação. }\end{array}$ \\
\hline & & 4 & Nivel intermédio \\
\hline & & 3 & $\begin{array}{l}\text { Confere alguma expressividade ao seu discurso, porém revela-se, por vezes, "apático", } \\
\text { "desmotivado", "indiferente". }\end{array}$ \\
\hline & & 2 & Nivel intermédio \\
\hline & & 1 & $\begin{array}{l}\text { Não confere qualquer expressividade ao seu discurso, revelando-se "monótono" e } \\
\text { "desmotivador". }\end{array}$ \\
\hline & \multirow{5}{*}{ 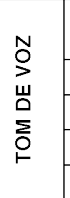 } & 5 & $\begin{array}{l}\text { Projeta a voz de forma totalmente adequada ao tipo de discurso e audiência (ex. enfatizando o } \\
\text { que é relevante). }\end{array}$ \\
\hline & & 4 & Nivel intermédio \\
\hline & & 3 & Adequa a voz ao tipo de discurso e audiência, porém usa um tom de voz monocórdico. \\
\hline & & 2 & Nivel intermédio \\
\hline & & 1 & Utiliza um tom de voz inadequado ao tipo de discurso e audiência (ex. inaudível) \\
\hline & \multirow{5}{*}{$\frac{\frac{O}{i}}{\frac{E}{\alpha}}$} & 5 & $\begin{array}{l}\text { Empreende um ritmo discursivo totalmente adequado ao discurso, dinâmico e contrastante, } \\
\text { captando a atenção da audiência. }\end{array}$ \\
\hline & & 4 & Nivel intermédio \\
\hline & & 3 & $\begin{array}{l}\text { Empreende um ritmo adequado, com algum dinamismo, captando, pontualmente, a atenção } \\
\text { da audiência. }\end{array}$ \\
\hline & & 2 & Nivel intermédio \\
\hline & & 1 & Ritmo totalmente inadequado e estático que conduz à dispersão da audiência. \\
\hline
\end{tabular}

Componente Não-Verbal - Indicadores da Competência Comunicativa Oral

\begin{tabular}{|c|c|c|c|}
\hline \multirow{15}{*}{ 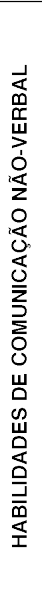 } & \multirow{5}{*}{ 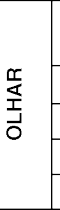 } & 5 & $\begin{array}{l}\text { Projeta um olhar abrangente, natural, dirigido aos colegas e professores, demonstrando } \\
\text { confiança e interesse. }\end{array}$ \\
\hline & & 4 & Nivel intermédio \\
\hline & & 3 & Projeta um olhar natural, "enfrentando" esporadicamente os colegas e professores. \\
\hline & & 2 & Nivel intermédio \\
\hline & & 1 & Não dirige o olhar à sua audiência, focando-se num ponto, por ex. teto, chão ... \\
\hline & \multirow{5}{*}{ 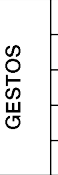 } & 5 & Recorre com naturalidade a gestos, como complemento à comunicação verbal. \\
\hline & & 4 & Nivel intermédio \\
\hline & & 3 & Recorre, com alguma frequência, a gestos, porém com pouca naturalidade. \\
\hline & & 2 & Nivel intermédio \\
\hline & & 1 & Não acompanha o seu discurso com gestos. \\
\hline & \multirow{5}{*}{ 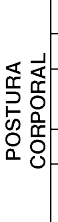 } & 5 & Manifesta uma postura correta, dinâmica e adequada ao longo do discurso. \\
\hline & & 4 & Nivel intermédio \\
\hline & & 3 & $\begin{array}{l}\text { Manifesta uma postura parcialmente correta, colocando, por vezes, as mãos nos bolsos, } \\
\text { encostando-se ao quadro ... }\end{array}$ \\
\hline & & 2 & Nivel intermédio \\
\hline & & 1 & $\begin{array}{l}\text { Manifesta uma postura incorreta e passiva ao longo do discurso, por ex. braços cruzados, mãos } \\
\text { nos bolsos. }\end{array}$ \\
\hline
\end{tabular}

